\title{
OPTIMAL HEDGE RATIO IN A BIASED FORWARD MARKET UNDER LIQUIDITY CONSTRAINTS ${ }^{1}$
}

\author{
Barbara Dömötör ${ }^{2}$ \\ Corvinus University of Budapest, Department of Finance
}

The paper investigates corporate hedging behavior in a theoretical model focusing on two important influencing factors: liquidity constraints affecting the funding opportunity of the firm and the extent of available hedging position, and speculative motive of risk management based on a bias of forward market. The optimal hedge ratio is analyzed in the function of three determining factors of the corporate utility function: the risk aversion ratio of the firm, the expected value of the hedge position, and the financing costs due to the hedging itself. The large empirical evidence of corporate over- and underhedge can be better understood in the presented framework.

Keywords: Corporate risk management, optimal hedge ratio, funding liquidity, biased forward markets

JEL classification: $\mathrm{G} 17, \mathrm{G} 32$

\section{INTRODUCTION}

Corporate risk management has an essential role in practice (Walter, 2014), its relevance is explained from different aspects in the financial theories. The main reason for corporate hedging in all of the theories is some imperfectness of the markets (Hommel, 2005): the presence of taxes (Smith and Stulz, 1985), transaction costs (Dufey és Srinivasulu, 1984), the asymmetric information among market participants (Myers and Majluf, 1984; Tirole, 2006), or financial distresses caused by unavailable financing (Smith and Stulz, 1985; Froot et al. 1993; Tirole, 2006).

Even the models based on the lack of financing neglect the financial consequences (upfront paying obligations, maturity mismatches, mark-to-market settlements of derivative positions, or cashcollaterals) of the hedging itself. Although the analysis of Froot et al. (1993) mentions the trade-off between the variability of future cash-flow and the fluctuation of cash in the interim period if the hedging position is to be financed, they do not analyze this problem further.

Models considering liquidity risk of hedging appeared in the early 2000's, by modeling either the possible liquidation of the hedging position in case of a failed margin call (Deep, 2002), or

\footnotetext{
${ }^{1}$ The paper is based on Chapter 4 of the thesis "Market risk hedging under liquidity constraints". (Dömötör, 2014)

2 e-mail:barbara.domotor@uni-corvinus.hu
} 
calculating the financing costs deriving from the credit spread to be paid to collateralize the loss of the position (Korn, 2003).

Rampini et al. (2014) analyze the contradiction between the theory and the empirical experience of the hedging behavior of financially constrained firms. They point that in contrast to the theory suggesting more risk management in case of more constraints, the larger and financially more stable corporations were found to hedge more. They model the trade-off between financing and risk management in a dynamic setting based on the collateralization need of all obligations.

The speculative motive of "hedging" appeared in the works of many authors (e.g. Holthauser, 1979; Rolfo, 1980), but the models usually assume an unbiased forward/futures market, therefore a zero expected return of the hedging position. Expected return, however, can derive from comparative advantage of some firms (Stulz, 1996) or better information of the management (Conclon et al., 2015) that can be used to enhance corporate value and leads to selective hedging. On the other hand, uncovered interest rate parity is found to fail in the pre-crisis period (Darvas, 2009) and persistent deviations even from the covered interest rate parity were detected after the crisis (Du et al., 2016) in most of the currencies, suggesting that speculation also has a role in FX-risk management. The effect of speculation on the currency futures market is investigated by Hossfeld and Röthig (2016).

The paper is structured as te following: first, the model of corporate hedging decision is presented, then an analytical solution is given for the lower and upper bound of the optimal hedge ratio. The next part quantifies the effect of the influencing factors through some simulations using predetermined sets of the parameters. The results show that the expected value of the hedge position has a crucial role in the hedging decision, causing both under- and overhedge to be optimal even for risk-averse firms.

\section{THE MODEL}

The model assumes a company being exposed to the change in the market price of its product, so its revenue and profit bear market risk. We assume furthermore that hedging of this open position in the form of forward agreements is available on the market. The spot price $(S)$ follows geometric Brownian motion (GBM) with an expected drift of $\mu$ and volatility of $\sigma$. According to the stochastic calculus the change of the forward price $^{3}(F)$ also follows a GBM according to Equation (1):

$$
d F=(\mu-r) F d t+\sigma F d w
$$

where $r$ stands for the risk-free logreturn and $d w$ - the change of the Wiener process - is a normal distributed random variable.

\footnotetext{
${ }^{3}$ Trading related costs, like transaction costs related to market liquidity (Váradi et al., 2012) are disregarded.
} 
In contrast to the models of Deep (2002) and Korn (2003), Equation (1) is not supposed to be a martingale, so the drift rate can differ from zero in either direction, depending on the relation between $\mu$ and $r$.

The model is built up as follows: the company decides at time 0 about the hedging amount $(h)$, in our case the amount sold on forward, given the production quantity of $Q$. The maturity of the forward agreement and realization of the production are at time 2, and during the lifetime of the derivative position the unrealized loss is to be collateralized at time 1 . We suppose, the firm can borrow the amount of the collateral from the market at a given credit spread and after the placed collateral the risk-free return is paid. The hedge ratio is unchanged in both periods. The behavioral model is discrete; as it reflects better the corporate hedging practice, and it contains lognormally distributed market price, based on Equation (1), similarly to the method of Monte Carlo simulations.

The corporate profit $(\pi)$ is realized at time 2 :

$$
\pi=S_{2} * Q-c(Q)+h *\left(F_{0}-S_{2}\right)+k * \min \left[h * \frac{\left(F_{0}-F_{1}\right)}{1+r_{e f f}} ; 0\right]
$$

The cost $(c)$ is a function of $Q$, the indices refer to the time, $r_{e f f}$ is the risk-free effective return and $k$ stands for the credit spread to be paid (above the effective return) by the hedging company, $k$ is considered to be constant.

The corporate decision making is to be modeled in a risk-return framework, so an increasing and concave - reflecting a decreasing marginal utility (risk aversion ${ }^{4}$ ) - corporate utility function is supposed, and the aim of the company is the maximization of its expected value. The model applies a CRRA (constant relative risk aversion) type utility function:

$$
U(\pi)=\frac{\pi^{1-\gamma}}{1-\gamma}
$$

where $\gamma$ is a measure of the risk aversion ${ }^{5}$.

The optimal hedge amount $(h)$, which maximizes the expected utility, meets the following requirement:

$$
E\left[U^{\prime}(\pi) *\left(F_{0}-S_{2}+k * \min \left[0 ; \frac{F_{0}-F_{1}}{1+r e_{f f}}\right]\right)\right]=0
$$

\footnotetext{
${ }^{4}$ For more about risk appetite, see Berlinger-Váradi (2015).

${ }^{5}$ Optimal hedge according to several riskiness measures is analyzed by Eshani and Lien (2015).
} 
Equation (4) can be written in the next form:

$$
E\left[U^{\prime}(\pi)\right] * E\left[F_{0}-S_{2}+k * \min \left[0 ; \frac{F_{0}-F_{1}}{1+r_{e f f}}\right]\right]=-\operatorname{cov}\left(U^{\prime}(\pi) ; F_{0}-S_{2}+k * \min \left[0 ; \frac{F_{0}-F_{1}}{1+r e_{f f}}\right]\right)
$$

where the $U^{\prime}(\pi)$ is the first derivative according to $h$, as described in Equation (6)

$$
U^{\prime}(\pi)=\left[S_{2} * Q-c(Q)+h *\left(F_{0}-S_{2}\right)+k * h * \min \left[0 ; \frac{F_{0}-F_{1}}{1+r e_{f f}}\right]\right]^{-\gamma}
$$

The sign of the left-hand side of Equation (5) is equal to the sign of the expected value of the short forward position, as the utility function is increasing. If the expected value is positive $(\mu<r)$ equality holds only if the covariance term on the right-hand side is negative. As the second variable in the covariance is affected negatively by $S_{2}$ and $F_{1}$, independently from the hedged amount, the negativity of the covariance requires the first part $\left(U^{\prime}(\pi)\right)$ to be a positive function of the stochastic variables. In the absence of financing costs $(k=0)$, this requires $h$ (the hedging amount) to exceed the quantity of the production $(Q)$. From this follows, that it is optimal to overhedge, similarly to the result of Holthausen (1979).

However funding liquidity risk (in the form of financing cost) reduces the optimal hedge ratio, as the effect of $F_{1}$ (being positively correlated with $\left.S_{2}\right)^{6}$ is positive for any positive value of $h$. The reduction of the optimal hedging depends on the level of the financing costs $(k)$. It can be similarly shown, that the negative expected value of the hedge position causes a lower than 1 optimal hedge ratio which is further reduced by the eventual financing costs.

In sum, this means that the hedging affects the corporate utility since the financing cost and the expected value of the hedge position influence the expected value of the profit. The effect of the financing cost is always negative; the expected value can have both negative and positive impact; while utility increases through variance-reduction. The result of this threefold effect is a function of the determining parameters: the corporate credit spread, the expected value of the hedge position and the corporate risk aversion factor.

As the profit is the function of two not perfectly correlated risk factors $\left(F_{1}\right.$ and $\left.S_{2}\right)$, risk cannot be eliminated perfectly in the above model, just at a given significance level. Despite the positive correlation of the risk factors, under extreme circumstances, the corporate profit can become negative at any hedging level. The worst outcome occurs, if the short hedge position is to be financed because of the increasing market price of the first period, but the market price falls in the second period causing an operating loss on the unhedged part of the firm's production.

\footnotetext{
${ }^{6}$ The positive correlation derives from the fact that the both $F_{1}$ and $S_{2}$ contain the same stochastic change of $S$ for the first period.
} 


\section{THEORETICAL BOUNDS OF THE OPTIMAL HEDGE RATIO}

The exact value of the optimal hedge ratio is to be calculated in the function of the parameters of Equation (5) numerically. The bounds of the optimum can be however determined analytically.

The optimal solution has to ensure a positive profit at any price evolution. The theoretically lowest value of $S_{2}$ equals to zero. By substituting $S_{2}=0$, Equation (2) takes the following form in Equation (7):

$$
\pi=-c(Q)+h *\left(F_{0}\right)+k * \min \left[h * \frac{\left(F_{0}-F_{1}\right)}{1+r_{e f f}} ; 0\right]>0
$$

In the absence of financing cost the lower bound of the hedge ratio $(h / Q)$ is the same as in the model of Korn (2003):

$$
\frac{h}{Q}>\frac{\bar{c}}{F_{0}}
$$

This means that the hedge ratio has to exceed the ratio of average cost to the initial forward price.

The minimal hedge amount has to cover not only the operating costs but the financing cost of the position as well. As the financing cost is an unlimited stochastic variable ${ }^{7}$, this coverage can be ensured only at a given significance level $((\alpha))$ that depends on the risk attitude of the firm. To get a non-zero lower bound for the hedge ratio, we suppose a maximum of the price increase $\left(\Delta F_{1 \max \alpha}\right)$ and substitute it into Equation (2). The result is the following:

$$
\pi=-c(Q)+h *\left(F_{0}\right)+k * h * \frac{\left(-\Delta F_{1 \max \alpha}\right)}{1+r e_{f f}}>0
$$

After the rearrangement of (9), the hedge ratio is:

$$
\frac{h}{Q}>\frac{\bar{c}}{F_{0}-\frac{\Delta F_{1 \max \alpha}}{1+r e_{f f}} * k}
$$

\footnotetext{
${ }^{7}$ As the price movement has no upper limit, the financing cost can be theoretically even infinitive, indicating that the hedge itself can cause infinite financing costs.
} 
The minimal hedge ratio, in this case, is given by the ratio of the average cost and the initial forward price reduced by the maximum of the financing costs at a certain $(\alpha)$ level. This ratio would ensure a positive end of period profit with a probability of $(\alpha)$, even if the hedge position caused financing costs.

The hedge causes financial loss if the market price increases, so the maximum of the hedge ratio is the level, where the financing cost and the negative value of the hedging position are counterbalanced by the realized higher operating income. As the price increase can be theoretically infinitive, a non-negative profit can be ensured only at a given significance level at any low level of the hedge ratio. Denoting the maximum of the price at maturity at $(\alpha)$ significance level by $F_{2 \max \alpha}=S_{2 \max \alpha}=F_{0}+\Delta F_{2 \max \alpha}$, and substituting it and the maximum of $F_{1}$ into Equation (2) we will get:

$$
\pi=\left(F_{0}+\Delta F_{2 \max \alpha}\right) * Q-c(Q)+h *\left(-\Delta F_{2 \max \alpha}\right)+k * h * \frac{\left(-\Delta F_{1 \max \alpha}\right)}{1+r e_{f f}}>0
$$

After rearrangement and simplification, the upper bound of the hedge ratio is given by (12):

$$
\frac{h}{Q}<\frac{F_{0}+\Delta F_{2 \max \alpha}-\bar{c}}{\Delta F_{2 \max \alpha}+\frac{\Delta F_{1 \max \alpha}}{1+r e_{f f}} * k}
$$

The numerator of the right-hand side of (12) shows the operative profit per unit without hedge that can cover the hedging costs per unit appearing in the denominator.

As shown above, the level of the financing costs $(k)$ moderates the measure of over- and underhedge. If $k$ goes up, the lower bound increases, while the upper bound decreases.

\section{EFFECT OF THE INFLUENCING FACTORS}

The optimal hedge ratio of the model is a function of corporate specific parameters: cost function, credit spread, risk aversion and the parameters of the forward price movement process: drift and volatility. In the following, the effect of two factors: liquidity (modeled by the corporate credit spread) and the expected value of the hedging position (drift of the forward price) are presented through the results of Monte Carlo Simulation ${ }^{8}$.

\footnotetext{
${ }^{8} 2000$ outcomes were generated with the antithetical variable method.
} 
The parameters of the simulation are summarized in Table (1).

1. Table: Parameters of the model

\begin{tabular}{|l|c|c|c|}
\hline \multicolumn{2}{|c|}{ Parameter } & Notation & Value \\
\hline \multirow{4}{*}{$\begin{array}{l}\text { Corporate } \\
\text { specific }\end{array}$} & Average cost & $c^{*}$ & $10 \%$ \\
\cline { 2 - 4 } & Credit spread & $k$ & $\begin{array}{c}\text { changing } \\
\text { variable }\end{array}$ \\
\cline { 2 - 4 } & Risk aversion & $\gamma$ & 2 \\
\hline \multirow{4}{*}{$\begin{array}{l}\text { Forward } \\
\text { price } \\
\text { process }\end{array}$} & $\begin{array}{c}\text { Drift } \\
\text { Volatility }\end{array}$ & $\sigma$ & $\begin{array}{c}\text { changing } \\
\text { variable }\end{array}$ \\
\cline { 2 - 4 } & rnitial forward \\
\cline { 2 - 4 } & $\begin{array}{c}\text { Riskless } \\
\text { return }\end{array}$ & $F_{0}$ & $10 \%$ \\
\hline
\end{tabular}

The cost function is assumed to be linear; the average cost is expressed as a percentage of the initial forward rate. The aim of the optimization was to find the hedge ratio that maximizes the expected utility. Figure 1 illustrates the results.

Figure 1: Optimal hedge ratio as a function of the credit spread and forward drift ( $\gamma=2$, volatility: $10 \%$, average cost $10 \%$ )

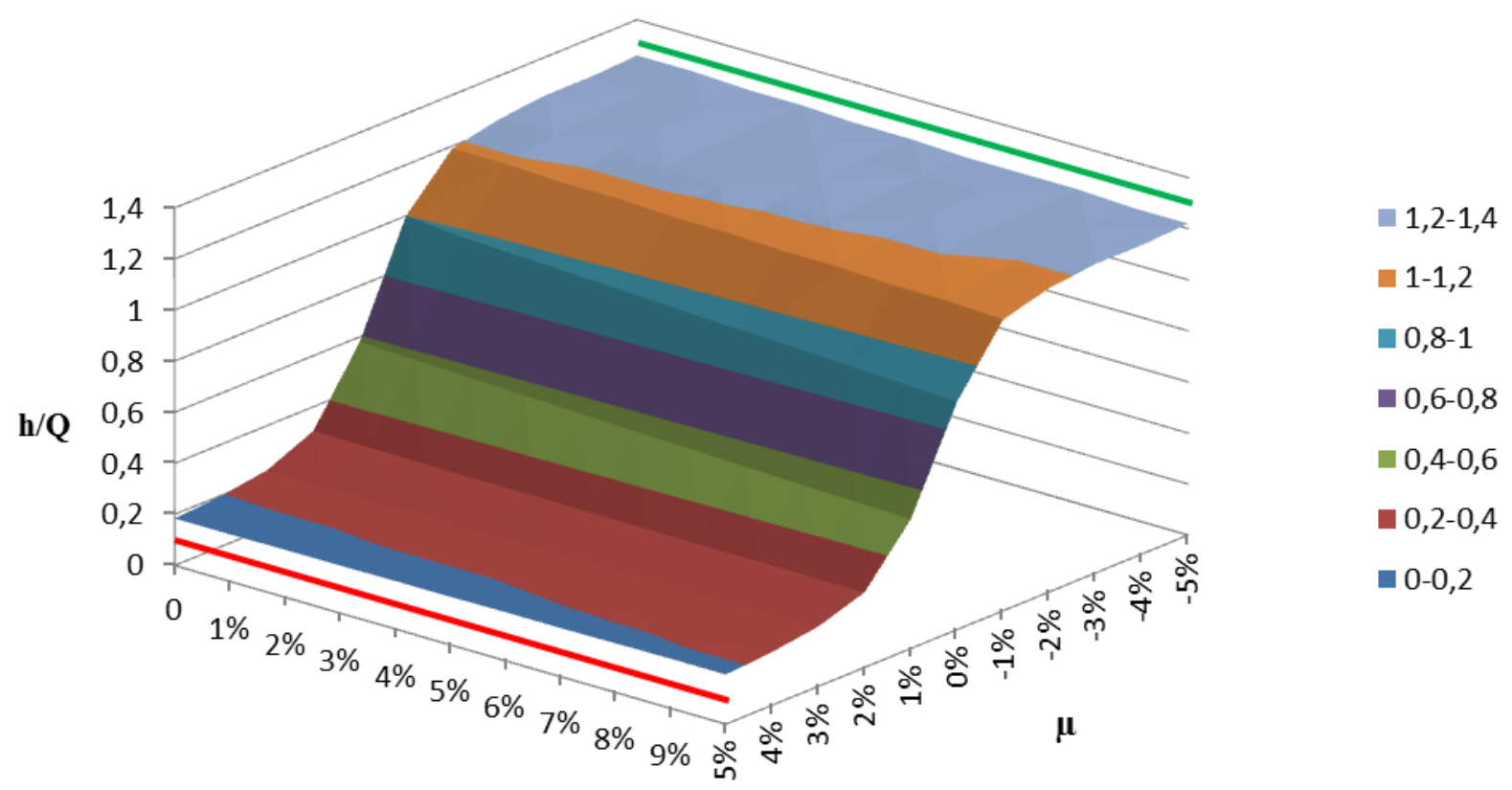

The effect of a constant credit spread is moderate, 1 percentage point increase in the credit spread causes the same decrease in the optimal hedge ratio if the expected value of the hedge is zero. In the 
case of a biased forward market, the financing cost affects the optimal hedging only by its effect on the minimum/maximum hedge ratio.

On the other hand, the expected value of the hedge position is very significant under the investigated parameters. A minor difference from zero drift leads to significant under- or overhedge in the optimum. 1-2\% positive (negative) drift of the forward price is enough to shift the optimal hedging level close to the lower (upper) bound. The bounds are shown by the red and green lines.

The forward drift of EURUSD currency-pair was about $-5 \%$ in the last years, justifying an essential (20-30\%) overhedge for euro exporters, while euro importers acted rationally by hedging less than $20 \%$ in the framework of the above model.

\section{CONCLUSION}

The variety of corporate hedging behavior is explained in the literature from many aspects. Considering the importance of funding liquidity, this paper highlights the speculative motive of the hedge, that derives from the non-zero expected value of the forward position. The optimal hedge ratio is modeled and the effect of the influencing factors is investigated. The analysis shows that although financing costs reduce the optimal hedge ratio, the effect of the expected value of the forward position is more significant, suggesting that this latter effect can better explain the empirical fact of corporate under- or overhedge.

\section{REFERENCES}

Berlinger, E., Váradi, K. (2015): Risk Appetite. Public Finance Quarterly (In Hungarian: Pénzügyi Szemle), 60(1), 1-15.

Conlon, T., Cotter, J., Gençay, R. (2015): Commodity futures hedging, risk aversion and the hedging horizon. The European Journal of Finance, 1-27.

Darvas, Zs (2009): Leveraged Carry Trade Portfolios. Journal of Banking \& Finance, 33(5), 944957.

Deep, A. (2002): Optimal Dynamic Hedging Using Futures under a Borrowing Constraint. Working Paper, Bank for International Settlements, Basle, 1629-1658.

Dömötör, B. (2014): Market risk hedging under liquidity constraints. Doctoral thesis, Budapesti Corvinus Egyetem

Du, W., Tepper, A., Verdelhan, A. (2016): Deviations from Covered Interest Rate Parity. Available at SSRN: http://ssrn.com/abstract $=2768207$

Dufey, G., Srinivasulu, S. L. (1984): The Case for Corporate Management of Foreign Exchange Risk. Financial Review, 19(3), 39-47. 
Ehsani, S., Lien, D. (2015): A note on minimum riskiness hedge ratio. Finance Research Letters, 15(November), 11-17.

Froot, K. A., Scharfstein, D. S., Stein, J. C. (1993): Risk Management: Coordinating Corporate Investment and Financing Policies. The Journal of Finance, 48(5), 1629-1658.

Holthausen, D. M. (1979): Hedging and the Competitive Firm under Price Uncertainty. The American Economic Review, 69(5), 989-995.

Hommel, U. (2005): Value-based Motives for Corporate Risk Management. in Risk Management, Chapter 3. 455-478., Springer, Berlin Heidelberg,

Hossfeld, O., Röthig, A. (2016): Do speculative traders anticipate or follow USD/EUR exchange rate movements? New evidence on the efficiency of the EUR currency futures market. Finance Research Letters, 18(August), 218-225.

Korn, O. (2003): Liquidity Risk and Hedging Decisions. Working Paper, University of Mannheim, Mannheim

Myers, S. C., Majluf, N. S. (1984): Corporate Financing and Investment Decisions when Firms have Information that Investors do not have. Journal of Financial Economics, 13(2), 187-221.

Rampini, A. A., Sufi, A., Viswanathan, S. (2014): Dynamic risk management. Journal of Financial Economics, 111(2), 271-296.

Rolfo, J. (1980). Optimal hedging under price and quantity uncertainty: The case of a cocoa producer. The Journal of Political Economy, 100-116.

Stulz, R. M., Smith, C. W. (1985): The Determinants of Firms' Hedging Policies. Journal of Financial and Quantitative Analysis, 20(4), 391-405.

Stulz, R. M. (1996). Rethinking risk management. Journal of applied corporate finance, 9(3), 8-25.

Tirole, J. (2006): The Theory of Corporate Finance. Princeton University Press, Princeton and Oxford

Váradi, K., Gyarmati, Á., Lublóy, Á. (2012): Virtual Price Impact on the Budapest Stock Exchange. (in Hungarian) Economic Review, 59(5), 457-507.

Walter, Gy. (2014): Corporate Risk Management. In: Financing Corporates in Practice. (in Hungarian) 244 p. Alinea, pp. 225-238., Budapest 